\title{
O DESIGN CENTRADO NO HUMANO NA ATUAL PESQUISA BRASILEIRA - UMA ANÁLISE ATRAVÉS DAS PERSPECTIVAS DE KLAUS KRIPPENDORFF E DA IDEO
}

\author{
Iana Garófalo Chaves', João Paulo Bittencourt ${ }^{2}$ e Cibele Haddad Taralli ${ }^{1}$ \\ ${ }^{1}$ Faculdade de Arquitetura e Urbanismo-Universidade de São Paulo \\ ${ }^{2}$ Faculdade de Economia e Administração - Universidade de São Paulo \\ iana@usp.br - bittencourtjp@usp.br - cibelet@usp.br
}

Artigo submetido em julho/2013 e aceito em dezembro/2013

\section{RESUMO}

O presente artigo possui como objetivo relacionar o discurso de design centrado no humano (DCH) apresentado na literatura de Klaus Krippendorff com os métodos propostos pela empresa IDEO, e analisar quais e como esses métodos vem sendo empregados na pesquisa em design no Brasil, através de artigos publicados nas duas ultimas edições do congresso P\&D.
A pesquisa é um estudo bibliográfico de caráter comparativo, que utiliza-se da análise do discurso. Desse modo, é possível observar que os métodos do DCH estão mais presentes nas fases inicial e intermediária das pesquisas, denotando a necessidade de um maior desenvolvimento de tais métodos na fase final dos estudos.

PALAVRAS-CHAVE: método de design, discursos do design, DCH

\section{THE HUMAN CENTERED DESIGN IN THE RECENT BRAZILIAN RESEARCH - AN ANALYSIS THROUGH PERSPECTIVE OF KLAUS KRIPPENDORFF AND IDEO}

\begin{abstract}
This paper aims to relate the discourse of human centered design (HCD) proposed in the literature of Klaus Krippendorff with the methods proposed by the IDEO company, and analyze which and how these methods have been employed in the brazilian design research through articles published in the last two editions of $P \& D$ congress. The research is a
\end{abstract}

bibliographical study with comparative character, which is used the discourse analysis. Thus, it is possible to observe that HCD methods are more present in the beggining and intermediate stages of research, emphasizing the need for further development of such methods in the final stage of studies.

KEYWORDS: design methods, design discourse, HCD 


\section{O DESIGN CENTRADO NO HUMANO NA ATUAL PESQUISA BRASILEIRA - UMA ANÁLISE ATRAVÉS DAS PERSPECTIVAS DE KLAUS KRIPPENDORFF E DA IDEO}

\section{INTRODUÇÃO}

Atualmente entre as metodologias de design que vem sendo praticadas e pesquisadas tanto no âmbito acadêmico quanto pelas empresas, tem sido focado o indivíduo, sujeito e/ou ao usuário dos produtos, serviço ou processo tornando-os elementos chave para o projeto e seu desenvolvimento. Conforme comentado por Giacomin, 2012 está mudança de ênfase é evidente na progressão do paradigma do design que têm evoluído e prosperado ao longo dos anos, começando com a ergonomia e movendo-se através de fatores humanos, usabilidade, design centrado no usuário, inclusão, design de interação, design empático, design de experiência do produto, design de experiência do cliente, design emocional, design emocional durável, branding sensorial, neurobranding, design de serviço e, por fim, mais recentemente, design centrado no ser humano.

Dentre os diversos pesquisadores que vem estudando e abordando em sua produção acadêmica o design centrado no ser humano destaca-se Klaus Krippendorff ${ }^{1}$, que atualmente é professor emérito de comunicação pela The Annenberg School for Communication, da University of Pennsylvania, Estados Unidos. Klaus Krippendorff é graduado na Alemanha em engenharia pela State Engineering School Hanover, e em design, no ano de 1961, pela extinta escola de design de Ulm. Desde a década de 1990 o design centrado no humano é um tema encontrado em suas publicações. Dentre sua produção é possível destacar o capítulo do livro Doctoral Education in Design: Foundations for the Future, intitulado Propositions of Human-centeredness: A Philosophy for Design, publicada no ano 2000, no qual ele propõe um discurso para o design baseando nas proposições do design centrado no humano.

Além dos vários pesquisadores que contribuem para o embasamento e conhecimento teórico e conceitual do assunto, a empresa americana IDEO ${ }^{2}$ destacou-se nesta área utilizando a abordagem do design centrado no humano para ajudar organizações públicas e privadas a crescerem e a inovar. As ferramentas e os métodos aplicados pela empresa foram compilados em um livro/manual denominado Human Centered Design - Kit de ferramentas, possibilitando a propagação das práticas utilizadas pelas equipes da empresa para outros profissionais que queiram aplicar esses métodos.

Nas recentes publicações brasileiras, a exemplo dos Anais das duas ultimas edições do Congresso Brasileiro de Pesquisa e Desenvolvimento em Design, realizadas nos anos de 2010 e 2012, o Kit de Ferramentas da IDEO é referenciado em diversos artigos, sendo em parte deles utilizado como metodologia para as pesquisas apresentadas. Dessa maneira, considera-se um referencial relevante na pesquisa de design centrado no humano.

O presente artigo possui como objetivo relacionar o discurso apresentado na literatura de Klaus Krippendorff com os métodos propostos pela IDEO de design centrado no humano, e analisar quais e como esses métodos vem sendo empregados na pesquisa em design no Brasil, através da análise dos artigos publicados nas duas últimas edições do Congresso Brasileiro de

\footnotetext{
${ }^{1}$ Informações obtidas através do site do pesquisador: http://www.asc.upenn.edu/usr/krippendorff .Acessado em julho de 2013

${ }^{2}$ Informações sobre a firma no site: http://www.ideo.com Acessado em julho de 2013
} 
Pesquisa e Desenvolvimento em Design. A pesquisa apresentada possui uma abordagem qualitativa, sendo assim um estudo bibliográfico de caráter comparativo, na qual utilizou-se a análise do discurso para o tratamento de dados. Conforme definição de Gill $(2012$, p.244) "Análise do discurso é o nome dado a uma variedade de diferentes enfoques no estudo de textos, desenvolvida a partir de diferentes tradições teóricas e diversos tratamentos em diferentes disciplinas".

\section{ABORDAGEM DO DESIGN CENTRADO NO HUMANO}

Dentre as metodologias que consideram o indivíduo em sua abordagem destaca-se o Design Centrado no Humano (DCH). Conforme comentado por Krippendorff (2000), o enfoque voltado para o ser humano ocorreu com o início dos anos de 1950 quando os até então produtos produzidos em série e com características funcionalistas, pertencentes à era industrial, passaram a ser considerados bens de consumo, informação e identidade. Os designers perceberam que os produtos não eram coisas, mas que tinham se tornado então práticas sociais, preferências e símbolos, e que os mesmos não atenderiam mais às necessidades de usuários racionais, e sim de compradores, consumidores e determinados públicos. Sendo assim o DCH preocupa-se com a maneira que as pessoas vêem, interpretam e convivem com artefatos (KRIPPENDORFF, 2000).

Segundo Giacomin (2012), o DCH possui suas raizes em áreas semi-científicas tais como ergonomia, ciência da computação e inteligência artificial, sendo baseado em técnicas que comunicam, interagem, enfatizam e estimulam o envolvimento de pessoas obtendo assim o entendimento de desejos, necessidades e experiências, que normalmente transcendem a própria percepção dessas pessoas.

No entendimento da IDEO, o DCH está inserido no contexto de design thinking, que é definido pelo presidente da empresa, Brown (2008, p.86), como sendo "uma metodologia que imbui a todo o espectro de atividades relacionadas à inovação com valores fundamentais do design centrado no ser humano". Ainda segundo Brown (2008), a abordagem em DCH mostra que a inovação juntamente com os negócios e a tecnologia também devem ser um fator relacionado às necessidades, comportamento e preferências humanas. $\mathrm{O} D C H$ vai através da observação, capturar insights inesperados e produzir a inovação, que refletirão exatamente o que os consumidores querem.

O DCH já é reconhecido atualmente nas normas técnicas internacionais, através da International Organization for Standardization, ISO 9241-210, intitulada como Ergonomia da interação humano-sistema, sendo a parte 210: Projeto centrado no ser humano para sistemas interativos. Essa norma remete a origem do DCH relacionada a ergonomia e sistemas, endossando assim a teoria apresentada por Giacomin (2012) acima. Segundo a apresentação da $A B N T^{3}$ :

\footnotetext{
"Esta parte da ABNT NBR ISO 9241 fornece requisitos e recomendações para princípios e atividades do projeto centrado no ser humano para todo o ciclo de vida de sistemas interativos computacionais. É destinada àqueles que gerenciam processos de projeto e se preocupam com a forma com que componentes, tanto de hardware quanto de software, de sistemas interativos podem aprimorar a interação humano-sistema."
}

\footnotetext{
${ }^{3}$ Informação obtida através do site http://www.abntcatalogo.com.br . Acessado em julho de 2013.
} 
Dentre as características definidas na norma ISO 9241-210, são abordadas a experiência do usuário e avaliação de design centrado no usuário. É necessária, portanto nesse ponto uma distinção entre o que seria o design centrado no usuário e design centrado no humano. Segundo Gasson (2003), a abordagem centrada no usuário apresenta métodos focados na solução de problemas predeterminados e técnicos, falhando assim em promover interesses humanos. Para atender a perspectiva centrada no humano, a alternativa seria focar na definição do problema juntamente com a sua solução. O autor ainda afirma que, tendo o design de sistemas como exemplo, a abordagem centrada no usuário possui uma pesquisa muito limitada, sendo seus aspectos de significados sócio-culturais e de contexto insuficientes para os designers produzirem um sistema centrado no humano.

\section{O DISCURSO DE DCH DE KLAUS KRIPPENDORFF}

Klaus Krippendorff possui várias publicações nas principais áreas de seu interesse do design, definidas pelo mesmo como sendo: Teoria da semântica dos produtos, Design centrado no humano, Princípios do design na era da informação, Pesquisa de design da interface humanocomputador, dentre outros ${ }^{4}$.

Dentre sua produção destacam-se na área do design centrado no humano o capítulo do livro intitulado: Propositions of human-centeredness: A philosophy for design, conforme comentado anteriormente. Além dessa publicação destaca-se o artigo: Design centrado no ser humano: uma necessidade cultural, que possui conteúdo bastante semelhante com ao capítulo do livro. Ambas as publicações datam o ano de 2000 e nelas o autor apresenta seis tópicos que o mesmo define como sendo um discurso de $\mathrm{DCH}$, sendo também consideradas por ele como seis áreas ainda carentes de desenvolvimento. Resumidamente o pesquisador define as mesmas da seguinte forma:

1- Formas de narrar modos de vida imagináveis.

Os designers devem alterar determinismos históricos, inventar futuros e fazer com que os mesmos sejam possíveis. Precisam articular esse futuro com sua própria linguagem.

2- A capacidade de reenquadrar concepções do presente de modo a fazer com que o imaginável pareça realizável.

O designer deve ter uma narrativa convincente a respeito de como o presente pode ser transformado em um futuro desejável, defendendo a possibilidade de realização das suas idéias e articulando seus objetivos com os stakeholders.

3- Uma retórica que estimule redes de stakeholders grandes o bastante pra fazer que o design progrida.

O design é mais efetivo quando incrustado na comunidade que exige participação no futuro que ele realiza. Sendo assim devem ser ensinadas técnicas colaborativas de projeto, envolvendo os stakeholders como participantes ativos.

4- Gerar conhecimento de segunda ordem.

\footnotetext{
${ }^{4}$ Informações obtidas através do site do pesquisador: http://www.asc.upenn.edu/usr/krippendorff .Acessado em julho de 2013
} 
Os designers devem entender o que fazem e também como os outros percebem o que eles fazem. Ou seja, um entendimento do entendimento (entendimento de segunda ordem), um conhecimento que é capaz de considerar o conhecimento dos outros.

5- Virtude e moral coletivas.

Os projetos dos designers devem atender a um número de stakeholders e não a população inteira já que também não é possível controlar todas as redes de stakeholders que emergem. Portanto, o designer deve ser encorajado a suspender os possíveis julgamentos finais e questionar seus próprios valores.

\section{6 - Um discurso crítico e indisciplinado.}

O design pode adotar e examinar conceitos e discursos de disciplinas mais estabelecidas, entretanto não deve utilizar os paradigmas dessas disciplinas de maneira acrítica. Na busca da legitimação do discurso em design, deve-se trabalhar com o foco no humano e não no objeto. 0 objetivo do designer é a realização de um futuro desejável, portanto a metodologia, linguagem e práticas desenvolvidas por esse profissional devem permitir a narrativa dessas possibilidades imaginadas por ele e aceitas pelos stakeholders.

No ano de 2007, Krippendorff escreveu o capítulo Semantics: Meanings and Contexts of Artifacts, do livro intitulado Product Experience. Nesse capítulo, o autor sugere quatro pilares conceituais que sustentam uma abordagem do DCH. Ao comparar os seis tópicos apresentados na publicação de 2000, com os quatro apresentados em 2007, é possível observar que alguns tópicos são semelhantes, alguns foram agrupados tornando-se um novo tópico, enquanto outros não foram mencionados. Os conceitos e os quatro pilares são apresentados de forma resumida a seguir:

\section{1- Entendimento de segunda ordem}

Esse tópico é semelhante ao da primeira definição do autor. O design é comprometido em projetar artefatos que vão ser experimentados por outros usuários de maneira diferente. Sendo assim, o designer não pode utilizar conceitos universais, ele deve entender como determinado artefato será compreendido no contexto de quem está em contato com o mesmo. Nesse sentido, projetar com tecnologia, sem utilizar o envolvimento do usuário e sem o entendimento humano é utilizar apenas o entendimento de primeira ordem.

\section{2-Significados}

Projetar artefatos para outros possibilita que esse objeto venha a se apropriar de significados para seu usuário, dentro das suas próprias concepções. O autor utiliza a semântica como estudo dos significados.

A chave do conceito de significado é o reconhecimento que, os seres humanos criam seus próprios mundos e se diferenciam através dos artefatos, não em termos físicos, mas de acordo com o que eles significam para as pessoas, incluindo a forma de comunicação entre eles. Assim, os significados não podem estar separados de como as pessoas interagem com a tecnologia que suas culturas criam e as tornam significativas.

\section{3- Rede de stakeholders}

Esse tópico está relacionado com os itens 2 e 3 presentes na primeira classificação do autor. O design não estará apenas relacionado aos interesses de quem irá utiliza-lo. Existem 
profissionais e pessoas que estão envolvidas e interessadas (stakeholders) para que o design seja produzido, portanto a rede de informações e ações entre essas pessoas devem ser consideradas para o design ser realizado. $O$ designers devem reconhecer o papel fundamental das partes interessadas e acolher os seus papéis ativos no projeto, sem considerar-se como um mentor do processo, mas como um participante ativo dessa rede também.

\section{4 - Interfaces}

O design de interfaces para humanos deve ir além da forma e da sua decomposição em sequência de ações humanas e respostas de artefatos sensório-motoras que podem ser monitorizadas, compreendidas, e dirigidas para experiências desejáveis.

Para projetar artefatos simples, é preciso saber como eles sustentam as práticas culturais de seus usuários. Conforme sugestão de Gibson (1979), de que nós não percebemos as coisas, mas o que elas oferecem que façamos, seria assim um erro descrever a forma física das coisas separadas de como a percebemos e agimos sobre elas. Ele sugere que nós não percebemos questões físicas e sim como as coisas podem nos afetar, tomando como exemplo um artefato qualquer, significa não perceber qual é seu peso em quilogramas, mas em saber se ele é fácil de ser levantado ou removível.

Entre os métodos que parecem atender aos preceitos do discurso do $\mathrm{DCH}$, destaca-se a metodologia desenvolvida pela empresa IDEO, conforme apresentação seguinte.

\section{METODOLOGIA DA IDEO}

A empresa americana IDEO é mundialmente conhecida por utilizar a metodologia centrada no humano com seus clientes e difundir suas práticas através de várias publicações. $O$ próprio presidente da empresa, Tim Brown, é autor de publicações que abordam o design thinking, utilizando a metodologia centrada no humano. Observando as diversas explicações e definições dos métodos encontrados no site da empresa, fica claro que a IDEO não possui um único caminho para solucionar os problemas destintos, mas sim uma gama de ferramentas para a criação do melhor método a ser utilizado em cada cenário.

Para o presente artigo, utilizou-se como referência a metodologia da IDEO presente no livro/manual denominado Human Centered Design - Kit de Ferramentas.

De forma resumida, o manual inicia apresentando o que define como lentes do $\mathrm{DCH}$. A primeira lente refere-se ao Desejo do usuário, começando pelas pessoas para as quais se está criando a solução, procurando ouvir e entender o que elas querem. Durante as várias etapas do processo de design, deve-se enxergar o mundo através desta lente. Uma vez identificado qual é o desejo do usuário, começa-se a examinar as soluções através das lentes da praticabilidade e da viabilidade, que vão ser utilizadas nas fases finais do processo.

Após a definição das lentes que devem ser consideradas para obter as soluções, são apresentadas três etapas do processo de estratégia do DCH, são elas: Ouvir (Hear), Criar (Create) e Implementar (Deliver). Durante o processo, o pensamento do designer alternará do concreto ao abstrato, identificando temas e oportunidades e, mais tarde, retornará ao concreto com soluções e protótipos. Essas etapas são definidas da seguinte forma: 


\subsection{Ouvir}

$\mathrm{O}$ ato de projetar soluções inovadoras e relevantes, que atendam às necessidades das pessoas, começa com o entendimento de suas necessidades, expectativas e aspirações para o futuro. Essa etapa diz respeito a como abordar as pessoas em seus próprios contextos para entender em profundidade os seus problemas.

\subsection{Criar}

Para transformar pesquisas em soluções para o mundo real, é preciso passar por um processo intermediário de síntese e interpretação. Isso requer filtrar e selecionar a informação, traduzindo insights sobre a realidade atual em oportunidades para o futuro. Esta é a parte mais abstrata do processo, quando se deve transformar necessidades concretas dos indivíduos em insights mais gerais sobre a população e modelos de sistemas. Com as oportunidades definidas, deverá ser adotado um ponto de vista generativo para criar centenas de soluções em brainstorms e rapidamente converter algumas delas em protótipos. Durante esta fase, as soluções são criadas somente com o filtro do Desejo, definido acima, em mente.

\subsection{Implementar}

Essa fase desafiará a equipe a criar os elementos necessários para que a solução tenha sucesso e para monitorar o seu impacto.

\section{ABORDAGEM INTEGRADA ENTRE KRIPPENDORFF $X$ IDEO E A RECENTE PESQUISA ACADÊMICA NO BRASIL}

Após o entendimento dos escritos de Klaus Krippendorff sobre DCH e o entendimento dos métodos praticados pela IDEO sobre o tema, foi possível estabelecer relações entre as duas propostas. As perspectivas, conforme foram apresentadas acima, possuem naturezas distintas, sendo uma com características mais abstrata e generalista a outra mais voltada para à ação e prática.

Sendo assim, após análise, foi proposta uma relação na qual buscou-se definir em qual das etapas da IDEO poderiam estar mais presentes e/ou relacionadas nos itens propostos por Krippendorff. Essa relação foi baseada nas descrições de cada elemento através da análise do discurso, e mesmo consciente de que um mesmo item poderia estar presente em mais de uma etapa, buscou-se definir a etapa mais significativa para cada um. Essa relação é apresentada na tabela 1, na qual cada linha apresenta uma etapa da metodologia IDEO e os itens das propostas de Krippendorff, que se relacionam com as mesmas. 
Tabela 1 - Relação entre as etapas IDEO com os itens das propostas de Klaus Krippendorff.

\begin{tabular}{l|l|l}
\hline \multicolumn{1}{c|}{ IDEO } & \multicolumn{1}{|c}{ KRIPPENDORFF (2000) } & \multicolumn{1}{c}{ KRIPPENDORFF (2007) } \\
\hline Ouvir & 4- Gerar conhecimento de segunda ordem. & $\begin{array}{l}\text { 1- Entendimento de segunda ordem. } \\
\text { 2-Significados. }\end{array}$ \\
\hline Criar & $\begin{array}{l}\text { 1-Formas de narrar modos de vida } \\
\text { imagináveis. } \\
\text { 2-A capacidade de reenquadrar concepções } \\
\text { do presente de modo a fazer com que o } \\
\text { imaginável pareça realizável. }\end{array}$ & \\
& 6-Um discurso crítico e indisciplinado & \\
\hline Implementar & $\begin{array}{l}\text { 3- Uma retórica que estimule redes de } \\
\text { stakeholders, grandes o bastante para fazer } \\
\text { que o design progrida. } \\
\text { 5- Virtude e moral coletivas }\end{array}$ & $\begin{array}{l}\text { 3- Rede de stakeholders } \\
\text { 4- Interfaces }\end{array}$ \\
\hline
\end{tabular}

De acordo com a proposta apresentada acima, as principais relações estabelecidas são: a etapa inicial "Ouvir" a qual está relacionada ao entendimento de segunda ordem (entender o entendimento da outras pessoas) e ao pilar de significados; ambos são itens que buscam a compreensão do humano e sua interação cultural e social no contexto em que vivem.

Na etapa intermediária "Criar" estão relacionados itens que tratam da capacidade dos designers perceberem novas realidades e oportunidades, e expressarem o modo como elas podem se tornar realizáveis. Além de o fato de ser crítico em relação aos paradigmas existentes nas outras disciplinas e no que é determinado por elas como sendo impossível, buscando assim criar uma própria linguagem e discurso, utilizando conhecimento de outras disciplinas mas não se apropriando dos discursos já existentes.

$\mathrm{Na}$ etapa "Implementar", os itens relacionados referem-se ao convencimento, participação e o envolvimento dos interessados na solução definida anteriormente, além de à suspensão de julgamentos finais relacionados também à solução encontrada. Isso vai possibilitar a consciência que, a solução atenderá a uma parcela dos interessados e não a todos eles, e por fim o item interface, que deve ir além da percepção física dos artefatos, sendo a etapa de implementação o momento de considerar esse aspecto.

Com essa relação estabelecida, tornou-se possível observar os itens da proposta de Krippendorff por uma lente que vem sendo bastante utilizada nas pesquisas de DCH atualmente, a metodologia da IDEO. Dessa forma, foi realizado um levantamento de artigos nos Anais do Congresso Brasileiro de Pesquisa e Desenvolvimento em Design, ocorridos nos anos de 2010 e 2012, com intuito de selecionar amostras de pesquisas que pudessem ser analisadas.

A pesquisa nestes Anais consistiu em averiguar inicialmente quais artigos referenciavam a IDEO em seus textos. Após realizar esse levantamento, foi possível classificar todos os artigos encontrados em dois grupos: em um deles o grupo de artigos que comentavam apenas a existência da firma IDEO e de seu métodos, ou citavam alguma definição ou trechos de suas publicações e no outro grupo de artigos que apresentavam pesquisas realizadas nas quais tenham sido utilizados a metodologia da IDEO no seu processo, ou seja artigos nos quais estavam presentes as etapas propostas do Human Centered Design - Kit de Ferramentas da empresa.

$O$ resultado encontrado nesse levantamento consistiu em: 
Para a edição de 2010, foram encontrados no total sete artigos mencionando a IDEO, sendo seis artigos citações da empresa e apenas um que utilizou as etapas de sua metodologia.

Para a edição de 2012, foram encontrados no total treze artigos mencionando a IDEO, sendo oito artigos citações da empresa e cinco que utilizaram as etapas de sua metodologia.

Para observar o emprego do DCH nas pesquisas, foram considerados então só os artigos do segundo grupo, que utilizaram as etapas da metodologia IDEO em sua pesquisa, totalizando então seis artigos. Os artigos selecionados foram:

\section{Anais P\&D 2010}

Artigo 1

\section{Anais P\&D 2012}

\section{Artigo 2 / Artigo 3 / Artigo 4 / Artigo 5 / Artigo 6}

Os artigos selecionados tiveram então seus discursos analisados, sendo extraídos dos mesmos, as informações referentes às etapas da pesquisa do $\mathrm{DCH}$. Apenas foram considerados nesse levantamento, as informações das etapas que consideraram os métodos de DCH da IDEO. Não foram considerados, portanto, na etapa Implementação uma pesquisa que chegou a definir um projeto como solução, mas não se utilizou dos métodos da IDEO referentes a essa etapa na solução. Para possibilitar as comparações entre os discursos dos artigos e apresentar suas ferramentas, as informações foram resumidas e dispostas na Tabela 2.

Tabela 2 - Etapas da IDEO encontradas nos seis artigos selecionados.

\begin{tabular}{|c|c|c|c|}
\hline & OUVIR & CRIAR & IMPLEMENTAR \\
\hline Artigo 1 & $\begin{array}{l}\text { Gravação dos grupos de alunos } \\
\text { durante o desenvolvimento do } \\
\text { projeto e suas discussões. } \\
\text {-Entrevistas com questionários } \\
\text { não-estruturados } \\
\text { disfarçados, com } 10 \text { alunos, } \\
\text { para conhecer o processo } \\
\text { projetual que eles adotam e } \\
\text { como eles fazem o } \\
\text { levantamento de dados } \\
\text { relativos aos usuários. }\end{array}$ & $\begin{array}{l}\text { - Desenvolvimento de } \\
\text { ferramentas baseadas nos } \\
\text { questionário. } \\
\text { - Gravações e relatórios } \\
\text { apresentados pelos alunos } \\
\text { durante a aplicação das } \\
\text { ferramentas estabelecidas. }\end{array}$ & $\begin{array}{l}\text { - Questionários de auto- } \\
\text { avaliação, comparando } \\
\text { as ferramentas com as } \\
\text { soluções projetuais } \\
\begin{array}{l}\text { apresentadas pelos } \\
\text { alunos. }\end{array}\end{array}$ \\
\hline Artigo 2 & $\begin{array}{l}\text { - Recrutar e Identificar pessoas- } \\
\text { chave para o entendimento do } \\
\text { contexto através de conversa: } \\
\text { as funcionárias do Banco de } \\
\text { Alimentos e de limpeza. }\end{array}$ & $\begin{array}{l}\text { - Ferramenta Brainstorm- } \\
\text { gerar alternativas a partir de } \\
\text { propostas em grupo. }\end{array}$ & \\
\hline Artigo 3 & $\begin{array}{l}\text {-Entrevista com usuários } \\
\text { relacionados ao meio } \\
\text { universitário da cidade de São } \\
\text { Carlos-SP. }\end{array}$ & $\begin{array}{l}\text { - Projeto empático - busca a } \\
\text { conexão profunda com } \\
\text { pensamentos e sentimentos } \\
\text { dos usuários a fim de criar }\end{array}$ & \\
\hline
\end{tabular}




\begin{tabular}{|c|c|c|c|}
\hline & $\begin{array}{l}\text { - Dinâmica de cartas } \\
\text { - Dinâmica de conceitos } \\
\text { sacrificiais. }\end{array}$ & $\begin{array}{l}\text { modelos mentais de } \\
\text { desenvolvimento do projeto }\end{array}$ & \\
\hline Artigo 4 & $\begin{array}{l}\text { - Método da Auto- } \\
\text { documentação, permitindo o } \\
\text { registro das experiências para o } \\
\text { designer entender como os } \\
\text { participantes desta pesquisa } \\
\text { percebem suas vidas e seus } \\
\text { contextos, técnica utilizada foi a } \\
\text { de criação de um caderno } \\
\text { impresso, contendo uma } \\
\text { questão em cada página. }\end{array}$ & $\begin{array}{ll}\text { - } & \text { Geração de cenários } \\
\text { - } & \text { Geração de personas }\end{array}$ & \\
\hline Artigo 5 & $\begin{array}{l}\text { - Recrutar e Identificar pessoas- } \\
\text { chave para o entendimento do } \\
\text { contexto com quem conversar }\end{array}$ & - Método de Brainstorm & \\
\hline Artigo 6 & $\begin{array}{l}\text { - Entrevista com questionário } \\
\text { pela internet com } 49 \text { mulheres. } \\
\text { - Entrevistas individuais, } \\
\text { pessoalmente, com mais seis } \\
\text { mulheres com o perfil } \\
\text { escolhido, para melhor } \\
\text { compreensão do seu cotidiano } \\
\text { e suas reais necessidades de } \\
\text { vestimenta no trabalho. }\end{array}$ & $\begin{array}{l}\text { - Moodboard: } \\
\text { mosaico de imagens que } \\
\text { apresentam em síntese a } \\
\text { solução pretendida. } \\
\text { - Personas: construção de } \\
\text { um ou mais personagens } \\
\text { que agrupem as } \\
\text { características dos } \\
\text { usuários. } \\
\text { - Storyboard: sequência de } \\
\text { imagens e respectivas } \\
\text { legendas que apresentam } \\
\text { das ações do serviço. }\end{array}$ & $\begin{array}{l}\text { - Mapeamento de } \\
\text { jornada de serviço: } \\
\text { representa a jornada de } \\
\text { serviço através } \\
\text { dos pontos de contato } \\
\text { entre a empresa e o } \\
\text { usuário. } \\
\text { - Blueprint: análise das } \\
\text { relações entre o usuário } \\
\text { e a empresa durante as } \\
\text { etapas do serviço } \\
\text { prestado, tendo como } \\
\text { foco o olhar do cliente. }\end{array}$ \\
\hline
\end{tabular}

Dessa forma, agrupando os métodos realizados em cada etapa em todos os seis artigos, temos a seguinte síntese apresentada na Tabela 3.

Tabela 3 - Síntese dos métodos da IDEO encontrados nos artigos.

\begin{tabular}{l|l|l}
\hline \multicolumn{1}{c|}{ OUVIR } & \multicolumn{1}{c}{ CRIAR } & \multicolumn{1}{c}{ IMPLEMENTAR } \\
\hline - Entrevista pela internet & - Moodboard & - Questionários de auto- \\
- Entrevistas individuais & - Personas & avaliação. \\
- Recrutar e identificar pessoas- & - Storyboard & - Mapeamento de jornada de \\
chave & - Brainstorm & serviço. \\
- Auto-documentação & - Geração de cenários & - Blueprint \\
- Dinâmica de cartas & - Projeto empático & \\
- Dinâmica de conceitos & - Desenvolvimento de & \\
sacrificiais. & ferramentas. & \\
- Gravação de atividades & - Gravações e relatórios. & \\
\hline
\end{tabular}

\section{DISCUSSÕES}

Dentre os artigos selecionados, conforme os critérios propostos, a primeira observação que pode ser feita é em relação à natureza dos mesmos. A quantidade de artigos se restringiu a 
seis, mesmo assim essa amostra apresenta pesquisas em diferentes áreas do design: educação, projeto de produto, meios eletrônicos e moda. Isso demonstra que o DCH através dos métodos propostos pela IDEO, não está presente somente em uma determinada área específica, mas em diversas vertentes do design.

A quantidade de artigos que abordam a IDEO encontrados no ano de 2012 foi maior que no ano de 2010; isso demonstra que a metodologia da empresa está se difundindo no âmbito da pesquisa acadêmica com o passar do tempo, bem como o $\mathrm{DCH}$, comprovando assim a relevância do estudo de ambos.

Analisando os quadros com as ferramentas encontradas nas três etapas, observamos que a primeira delas Ouvir foi contemplada em todos os artigos, sendo a que possuiu uma maior variedade de tipos de ferramentas empregadas. Isso demonstra que, além da preocupação dos pesquisadores em realizarem essa etapa de forma concisa para obter uma quantidade significativa de informações, existe também uma busca pelo método mais adequado a ser empregado em cada caso, não havendo, portanto, uma convenção ou padrão de métodos por parte dos pesquisadores. Observando os dados encontrados através da lente dos itens propostos por Krippendorff que foram relacionadas a etapa Ouvir, é possível afirmar que todos os autores buscaram em suas pesquisas um entendimento de segunda ordem e que a maioria das ferramentas utilizadas também auxiliaram em um entendimento dos significados dados pelas pessoas envolvidas aos artefatos e serviços em questão.

A etapa 'Criar' também foi contemplada em todos os artigos e contou com uma variedade de tipos de ferramentas. Por ser tratar da etapa abstrata dentro da metodologia IDEO, torna-se mais difícil de encontrar a descrição de suas ferramentas nos próprios textos, e também mais difíceis de serem analisadas, entretanto, é possível averiguar que a maioria das ferramentas utilizadas, salvo o design empático, foram as mais tradicionais encontradas e praticadas também em outras metodologias, não havendo, portanto, muita ousadia por parte dos pesquisadores nessa etapa, em utilizarem métodos da IDEO menos convencionais. Analisando os dados encontrados através da lente dos itens propostos por Krippendorff relacionados à etapa 'Criar', pode-se observar que as ferramentas utilizadas propõe soluções que narram modos de vida imagináveis e realizáveis, entretanto, não foi possível perceber nas descrições da maioria dos artigos a preocupação com um discurso crítico, que pudesse questionar os paradigmas de outras disciplinas que o design utiliza, e a busca por um discurso próprio. Apenas o artigo 1 que está relacionado à educação e a procedimentos projetuais para o design, consegue se aproximar da proposta deste item.

A etapa 'Implementar' foi a etapa menos privilegiada pelos pesquisadores, em relação à aplicação dos métodos da IDEO. A maioria dos artigos selecionados apresentaram uma solução projetual, entretanto, apenas dois deles utilizaram métodos de DCH aplicados a essa solução. Os métodos apresentados relacionam-se a avaliação da solução, e também o aspecto do usuário, não sendo utilizadas ferramentas, por exemplo, mais direcionadas para questões de efetividade, medição de progresso e sucesso das soluções. Analisando os dados encontrados através da lente dos itens propostos por Krippendorff relacionados à etapa 'Implementar', pode-se observar que em relação ao discurso que deve estimular os stakeholders, os métodos utilizados abrangem parcialmente essa atenção por envolverem junto aos designers, as pessoas interessadas. Já o item virtude e moral coletivas, não foi possível ser percebido nos artigos, uma vez que não ficou explicitado e nem foi narrado, questões morais entre os stakeholders e/ou julgamento a respeito 
das definições da solução definida. O item interface também não pode ser percebido devido à limitação das ferramentas encontradas e por elas não explicitarem essa abrangência.

\section{CONSIDERAÇÕES FINAIS}

A relação entre os discursos de Klaus Krippendorff e a metodologia da IDEO, definiu uma lente, através da qual foi possível analisar uma amostra de artigos recentes das pesquisas em design no Brasil. A análise de discurso desses artigos possibilitou observar que dentre as etapas Ouvir, Criar e Implementar, a etapa 'Ouvir' é a que mais apresenta variação de ferramentas DCH praticada pelos pesquisadores, demonstrando ser assim a fase mais desenvolvida da metodologia pelos praticantes.

A etapa 'Criar' apresentou ferramentas do DCH mais tradicionais, mesmo assim com uma variação significativa.

A etapa 'Implementar' foi a menos contemplada nos artigos, não sendo os métodos de DCH referentes a essa etapa, empregados por grande parte dos autores dos textos.

Em relação aos itens presentes no discurso de DCH de Klaus Krippendorff, pode-se afirmar que as atuais pesquisas desenvolvidas vem contemplando grande parte dos mesmos, legitimando assim sua importância e sua presença nas prática do $\mathrm{DCH}$, ressaltando ainda o caráter precursor do pesquisador que escreveu o discurso sobre o tema no ano 2000.

Dessa forma, pode-se dizer que existe uma inserção e prática mais acentuada, dos métodos DCH nas fases inicial e intermediária das pesquisas. Na fase final, observa-se que os designers propõe uma solução projetual, entretanto, não é comum essa solução estar definida com a aplicação de métodos de DCH pertencentes a essa fase. Isso demonstra que é ainda preciso um amadurecimento por parte da pesquisa que utiliza o $\mathrm{DCH}$ no Brasil em relação ao emprego de seus métodos na etapa final dos trabalhos, bem como um maior desenvolvimento dos itens do discurso de Krippendorff, que também se relacionam à essa etapa.

\section{REFERÊNCIAS BIBLIOGRÁFICAS}

1. BROWN,T. Design Thinking. Harvard Business Review. Junho, 2008. http://www.ideo.com/images/uploads/thoughts/IDEO_HBR_Design_Thinking.pdf. Acessado em julho de 2013, p. 84-92.

2. CIPOLLA,C.; VIEIRA, T. Design de serviços possibilitando a diminuição no consumo de roupas. In: X CONGRESSO BRASILEIRO DE PESQUISA EM DESIGN, São Luís - MA, Anais... São Luís: EDUFMA, 2012, p. 8357-8371.

3. DANTAS, D. Procedimentos projetuais para o design centrado no usuário aplicados ao ensino de projeto de produto. In: IX CONGRESSO BRASILEIRO DE PESQUISA EM DESIGN, São Paulo SP, Anais... São Paulo: Blücher e Universidade Anhembi Morumbi, 2010, p.2638-2646.

4. GARBULHO,G. S.; FLEURY, A. L. Som da Cidade: uma reflexão sobre a contribuição do Design Thinking em projetos para a indústria cultural. In: In: X CONGRESSO BRASILEIRO DE PESQUISA EM DESIGN, São Luís - MA, Anais... São Luís: EDUFMA, 2012, p. 3367-3378. 
5. GASSON, S. Human-Centered vs. User-Centred approaches to information system design. The Journal of Information Technology Theory and Application (JITTA), v. 5, n. 2, p. 29-46, 2003.

6. GIACOMIN, J. What is Human Centred Design?. In: X CONGRESSO BRASILEIRO DE PESQUISA EM DESIGN, São Luís - MA, Anais... São Luís: EDUFMA, 2012, p.148-161.

7. GIBSON, J.J. The Ecological Approach to Visual Perception. Boston: Houghton Mifflin.1979.p.350.

8. GILL, R. Análise de Discurso. In: BAUER, M. W.; GASKELL,G. (orgs) Pesquisa Qualitativa com texto, imagem e som: um manual prático. Petrópolis-RJ: Vozes, 2012. p. 244-270.

9. IDEO. HCD - Human Centered Design: Kit de ferramentas. EUA: Ideo, 2009. 102 p. Disponível em: <http://www.ideo.com/work/human-centered-design-toolkit/>. Acessado em julho de 2013.

10. KORBES,R.; FREIRE, K.F.; DEBIAGI,C.C. Contribuições do design estratégico para o desenvolvimento de um negócio de moda: o caso do Bureaux 464. In: X CONGRESSO BRASILEIRO DE PESQUISA EM DESIGN, São Luís - MA, Anais... São Luís: EDUFMA, 2012, p. 3816-3827.

11. KRIPPENDORFF, K..Propositions of Human-centeredness: A Philosophy for Design. In: DURLING, D.; FRIEDMAN, K. (Eds.). Doctoral Education in Design: Foundations for the Future. Staffordshire (UK): Staffordshire University Press, 2000.p.55-63.

12. KRIPPENDORFF, K.; BUTTER, R. Semantics: Meanings and Contexts of Artifacts. In SCHIFFERSTEIN, H.N.J.; HEKKERT, P. (Eds.). Product experience. New York: Elsevier, 2007.p.353-376.

13. KRIPPENDORFF, Klaus. Design centrado no usuário: uma necessidade cultural. Estudos em Design, Rio de Janeiro, v. 8, n. 3, p. 87-98, 2000.

14. SPERB,D.Q.; CAETANO,R. M.; CEREZER, L.; DIAS, A. M.; MILNE, M.L.A.; SAUER,L.Estadiômetro ergonômico de baixo custo: $O$ caso da Fundação Gaúcha de bancos sociais - FGBS. In: X CONGRESSO BRASILEIRO DE PESQUISA EM DESIGN, São Luís - MA, Anais... São Luís: EDUFMA, 2012, p. 7069-7074.

15. SPERB, D.Q.; CAETANO, R. M.; CONCI, M.; DIAS, A. M.; MILNE, M.L. A.; SEIBEL, M. K. O Ergodesign e projeto de produto: $O$ caso da fundação gaúcha dos bancos sociais - FGBS. In: X CONGRESSO BRASILEIRO DE PESQUISA EM DESIGN, São Luís - MA, Anais... São Luís: EDUFMA, 2012, p.923-935. 